\title{
The Limits of Open Innovation: A Literature Review and Research Agenda
}

\author{
Summer McGuckin \\ DiLab, San Diego State University \\ smcguckin1999@sdsu.edu
}

\author{
$\mathrm{Nan} \mathrm{Su}$ \\ DiLab, San Diego State University \\ nsu2@,sdsu.edu
}

\author{
Kaveh Abhari \\ DiLab, San Diego State University \\ kabhari@sdsu.edu
}

\begin{abstract}
Open Innovation (OI) has become a popular method of value co-creation over the past two decades. While OI offers many benefits, it holds a high failure rate. Through a systematic literature review, this paper identifies 15 common limitations of OI that contribute to this high failure rate at three levels: organizational, operational, and individual. Accounting for these limitations and their relationships, we develop a framework for OI's critical success factors. This paper also offers an agenda for future research and makes contributions toward understanding OI systems and their governance from a practical standpoint.
\end{abstract}

\section{Introduction}

Knowledge management systems allow organizations to create open and collaborative digital platforms that improve innovation capacity by exploiting flows of knowledge [1], [2]. These systems help organizations to establish Open Innovation (OI) processes and work collaboratively with internal and external stakeholders to develop creative solutions [3]-[5]. However, opening up the innovation process to external knowledge exploration and exploitation remains a challenging task for many organizations [6], [7]. Although proponents of OI have long argued that essential knowledge for sustained innovation lies beyond an organization's boundaries [8], they fall short in documenting obstacles hindering OI's successful implementation [9]-[13]. Instead, previous studies have mainly articulated the general logic of OI, described the workings of some well-known networks, and examined the benefits of engaging external actors in new product development (e.g. [14]-[18]).

$\mathrm{OI}$ is defined as a distributed innovation process based on purposively managed knowledge flows across organizational boundaries to accelerate internal innovation and expand the market from the use of internal knowledge [19]-[21]. While OI processes in tandem with knowledge management systems can potentially facilitate and enhance the innovation process and outcomes [22], [23], the downsides and the limits of this openness remain understudied [9], [10]. Further research on the limitations of OI is more needed than ever since in the last few years, many companies closed their customer innovation communities, OI marketplaces were abandoned, and innovation intermediaries filed for bankruptcies (e.g. [9], [24]). Even with incentives, the OI models sometimes cannot reach the most effective innovation results [25]. Besides, the cost of implementing and running an OI model sometimes does not justify its benefits [26], [27]. Research also showed that OI does not necessarily reduce the risk or failure rate of new products [9], [28].

OI can fade due to many reasons [11]. Difficulty in OI implementation, complexity in the OI environment, and uncertainty in OI results stem from the limitations of OI models that remain understudied [29]-[32]. Hence, understanding 'false-negatives' and 'false-positives' in the innovation process remain a central concern for OI adoption [12], [13]. In this study, we conducted a systematic literature review to investigate and document the limitations of OI. This type of review is critical to the development of a comprehensive understanding of this research domain and future research avenues [33]-[37]. This study is to establish an integrated foundation and common language to guide future research aiming at understanding and minimizing OI failures. After the meta-synthesis of the recently published articles, we categorized the results (OI failure factors) into 15 subcategories and three categories. For each group, we identified and discussed the key limitations that affected OI strategies, processes, and actors. This study contributes to the literature a theoretically grounded foundation for theorizing and examining OI models and their viability. Our findings also provide a view on OI limitations that holds relevance for the OI platform design with implications for OI governance.

\section{Methodology}

We conducted a systematic literature review based on recommended guidelines [38], [39] to gather the most recent articles from influential journals and authors 
within the OI domain. We used the ABS 2018 list to identify top-tier journals $\left(4^{*}, 4\right.$, and 3$)$ published in Information Management, Innovation, and Entrepreneurship and completed the list by highimpact journals such as Internet Research that have recently published OI research. The list of journals is provided in Appendix A. We searched through 56 journals and narrowed our search to work published within the last two years to ensure currency.

To identify articles, we searched for the presence of the term "Open Innovation" in the title, keywords, or abstract. Then, we documented the names and year of publication for each article selected, as well as the OI model, context, type of study, and unit of analysis. The first author reviewed abstracts for each of the articles in the sample to determine the relevancy. When an abstract was inconclusive, the full paper was reviewed to see if the author(s) discuss OI 'limits', 'limitations', 'challenges', or 'failures'. The selection of the articles was verified by the second author.

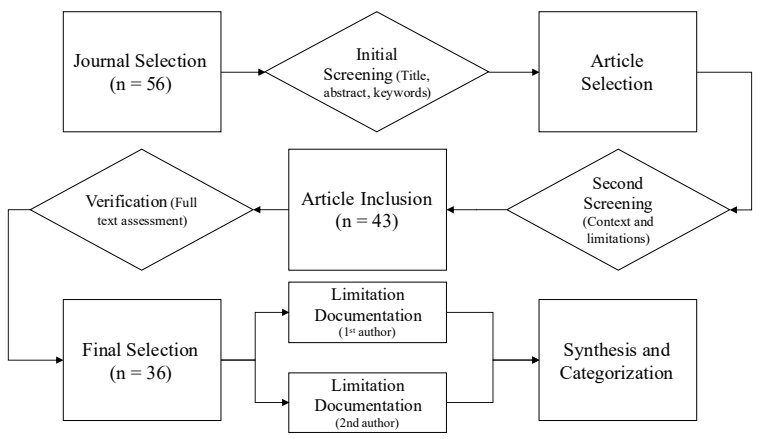

Figure 1. The process of literature review

In the next step, we narrowed our research to 36 papers that discussed the limitations of OI models. To do so, we focused on the articles that either present a case of OI failure, discuss the OI limitations in general, or explicitly evaluate the limitations of an OI model. The OI models identified in this review included opensource community (OSC), innovation marketplace (contest), user (customer) innovation, crowdsourcing, and social product development (SPD). OSCs are dedicated to developing non-proprietary software or hardware solutions. Innovation marketplaces are thirdparty (intermediary) platforms that connect problem owners to a large community of potential problems solvers mainly through the organizing of innovation contests. User innovation refers to consumer coproduction or participatory design that entails direct or indirect customer involvement in R\&D processes, usually in the initial development phases. Crowdsourcing models solicit creative ideas or microtasks from a broad community on a corporate or a third-party platform. SPD models use social mechanisms to mobilize individual inventors in support of new product development. Making note of the context of OI discussed in each of the articles also allowed us to see a diverse picture of OI literature in the last two years. Industry topics ranged from finance to manufacturing, including the pharmaceutical sector.

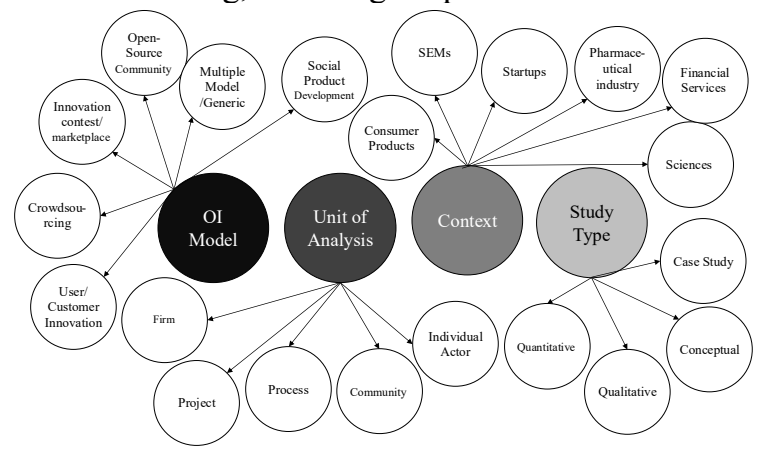

Figure 2. Types of research articles reviewed

We then categorized the limitations of OI based on their similarities into fifteen categories with clear definitions, highlighting examples of each as well as the OI model described in each article. Comparing and contrasting these categories, and following prior research (e.g. [20], [21]), we clustered the limitations in three groups associated with organizational, operational, and individual-level challenges. These three groups also correspond with three key units of analysis that emerged as the result of this review.

Organizational limitations are mainly associated with limitations that require strategic resources or strategic decisions (e.g., decisions concerning cost, structure, policies). These limitations are thus related to the implementation and governance of $\mathrm{OI}$ independent from their inbound/outbound orientation [31], [40], [41]. Operational limitations are mainly associated with managing OI projects, from incentivizing external actors to time management and coordination. While organizational factors correspond with the overall architecture of OI, operational factors are focused on the operationalization of the OI process and its core activities [36], [42]. Lastly, individual limitations are challenges related to individual actors participating in the OI processes [12]. Examples of these limitations include the lack of knowledge or counterproductive behavior of contributors. These limitations were discussed differently in the literature (e.g. [43], [44]) since innovation sponsors have less control over them due to their exteriority [45]. Hence, they may need different mechanisms to recognize.

\section{$3 \quad$ Findings}

\subsection{Organizational level}

The OI limitations at the organizational level are mainly related to how an organization plan, implements, and governs OI strategies. These 
limitations are related to OI vision, resources, structure, implementation, and compliance. Much of the research we identified in this review discussed OI from this perspective.

Lack of Clear Vision. Defining clear goals and developing a clear plan for value creation are essential in the early stages of OI. OI often develops from a need to address R\&D challenges, meet customer demands, or seize market opportunities [46]. Hence, the formation of an OI system within an organization or as a new organization is often organic and lacking in a clear vision [47]. This can prove to be an issue hindering OI organizations from surviving and thriving [47]. Falling short in communicating the goals with all partners can also limit OI. Articulating ideation goals is crucial to ensuring that organizations remain on track to reaching their vision [6], [27]. As external actors contribute to ideation, there becomes a greater need for a unified strategy and well-defined goals; otherwise, OI progress may be stalled [47].

Resource Constraints. The most prevalent OI organizational limitation is resource constraints [24]. Whether the issue was due to poor resource allocation or a lack of resources available to use, this was a common limitation throughout our review. Poor resource allocation is the root of OSC struggles in both value creation and capture [6], [48]. Similarly, OI models like SPD platforms may face challenges in allocating resources to balance the exploration and exploitation of opportunities that originate across their boundaries [49]. From a broad strategic viewpoint, resource allocation is an issue of finding the right balance between competing priorities. For example, OI practices come with a prohibitive cost [40] associated with extending a firm's resources and processes to external actors [27]. Research on this limitation reveals that $70 \%$ of firms cite financial pressure as the root of their struggle to effectively adopt OI practices [50]. Resource constraints may prompt organizations to redefine their overall goals or consider a different approach to strategizing OI. For example, in the science industry, OI and other collaborative practices can act as more of a barrier than a tool because of the high demand for resources [51].

Lack of Structure. Lack of structure can further exacerbate the issues associated with resource allocation [45]. This could include a lack of hierarchical structure, but also the lack of a formalized internal innovation process [50], [52]. Without a clearly defined organizational structure, external actors struggle with determining how to contribute meaningfully to the OI process [45]. For example, in OSC, the value co-creation networks are created without a solid hierarchical structure and no clearly defined authority. The organic form of these networks can result in complex relationships between actors that may lead to governance challenges [6]. Moreover, a lack of structure within an organically formed network also encourages an abundance of ideas, not all of which can be invested in. Organizations may face the loss of many opportunities without the infrastructure necessary to give potential solutions generated by OI a chance [27]. Another potential problem related to the lack of well-defined structure is the assumption of responsibilities among the actors, especially in hybrid innovation strategy management [53]. While all these factors are considered important constraints, the lack of cooperation within the organization is considered the least important constraint of the OI process [50], [54], yet it should still be considered as a possibility.

Implementation Challenges. Following the planning stage and deciding on the structure comes the implementation of OI practices where a firm may face additional limitations [24], [47]. There are several risks associated with changing a firm's approach to value cocreation that need to be considered during the implementation phase. First, strategic risks may arise if the adoption of OI practices does not fit organizational goals [55]. Alignment with the strategic objectives is key to the successful implementation of an OI model [29], [55]. Second, the firm's shifting the allocation of their resources may face different challenges from managing innovation performance to meeting market demand [40]. These risks can be decreased with proper planning and coordination but exist, nevertheless [27], [41], [56]. Third, the scope of OI implementation would limit the success of OI [47], [57]. Firms are affected by varying degrees of scope constraints - too big to manage or too small to be effective. [40], [51]. Lastly, we must consider the effects of changing an organization's existing workflow to incorporate OI practices and the effect that may have on the internal innovation team [58]. Lack of willingness to cooperate with new practices can hinder OI as well.

Compliance Concerns. By extending opportunities to those outside the organization, firms also open themselves up to potential legal trouble. The risk of crucial company information being mishandled or abused only increases as more actors become involved in the process [8], [59]. At an organizational level, this can be a barrier to effective OI. Likewise, governmental and local regulations can often become roadblocks for innovative practices [24]. While they exist to protect intellectual property rights and prevent abuse of information, such requirements may be so restrictive that OI practices simply cannot succeed [60]. Constricting and ineffective public policies can discourage organizations from implementing OI or delay the process of innovation [61]. Firms facing limitations by such policies at the strategic level will not be able to plan and implement OI in a way that best 
fits their needs and objectives [47], [62]. For OSC, security and licensing requirements also present significant challenges [47], [61]. For SMEs, the receipt of government subsidies or grants may do more harm than good as they come with conditions that do not support collaborative innovation.

\subsection{Operational level}

The operational level of a firm's OI activities is related to the firm's ability to manage decentralized processes that usually involve participants outside the organization [63]. In our study, we have identified and categorized several limitations related to actor engagement, coordination, quality assurance, time, technology, identification, and security.

External Community Engagement. At the operational level, inadequate compensation could become a limiting factor in engaging qualified external partners. For example, research has shown the importance of reward systems in engaging and motivating external actors to sustain OI communities like innovation marketplaces and SPD platforms [64], [65]. Lack of fair compensation can lead to additional challenges in the closing phase due to the lack of commitment among the actors [47]. Mechanisms to engage external actors are not limited to reward systems and monetary compensation; for example, providing learning and networking opportunities can enhance engagement and participation [66].

Coordination Constraints. Organizations face coordination constraints when adopting OI. As more people get involved in the process, there are more people and tasks to balance. The collaborative process can also present a challenge for centralized control when there are too many individual innovators involved [45]. Managers that are unable to navigate this complexity may struggle to lead OI effectively [52]. This includes both monitoring of participation and effective integration of contribution [67]. Without strong leadership and centralized control, these partners may struggle to coordinate on a strategy and overall direction [68].

Quality Assurance Issues. An abundance of information can both help and hurt the OI process. In general, adequate participants will bring an excellent selection of knowledge for an innovative project. However, information overload, among other factors, may prevent OI organizations from recognizing, assimilating, or exploiting high-quality ideas. For example, a study on complimentary products found that those products developed with OI platforms are subject to unpredictability [53]. Due to the nature of many OI platforms, which includes co-governance [65], the individual innovators or third parties are less restricted by the standard operating procedures required by the sponsoring organization; therefore, the quality of the products becomes difficult for the sponsor to maintain [9], [69].

Time Constraints. Both managerial skills and project coordination are necessary for OI to thrive, but time constraints can stall progress [47]. Hence, lack of time was cited as a barrier to the success of OI [23], [47]. Delays at any level of the innovation process can be a result of a multitude of factors, including poor resource allocation, ineffective leadership, and a lack of strategy [47]. OI takes time to plan, implement, and create value. Lack of realistic time estimates for OI projects may create false expectations among the stakeholders and lead to resource depletion and project failure [51].

Technological Affordances. The importance of employing the right technology has frequently been cited in OI research [23], [65], [70], [71]. OI organizations with limited IT-related capabilities may suffer from limited absorptive capacity which, in turn, may jeopardize the OI performance [70]. For example, excessive collaboration may lead to the problem of information overload and thus become a challenge when filtering valuable information and making economic decisions [27]. With the right technology, the process of absorbing and synthesizing such immersive knowledge from various sources may become challenging itself [52] and thus, requiring highly compatible knowledge management within the organization [70], [72]. Additionally, OI platform technology plays a significant role in engaging external actors and keeping them motivated, informed, and organized. Hence, having a strong knowledge management system in place is crucial.

Identification Limitations. The abundance of individual innovators participating in an OI platform may limit the sponsoring organization's ability to keep track of each participant's contribution and responsibilities, thus losing control over OI operation [73]. Anonymous contributions are often seen in online open communities such as Wikipedia. The OI community, like OSC, is not an exception [45]. These communities engage both identified and anonymous peripheral contributions (APC) [73]. While the sponsoring organization can track the contributions of identified peripheral contributions (IPC), it cannot trace back to the actor of an APC of a specific project. Studies have shown that it is ideal for a sponsoring organization to maintain a uniform anonymity level and a good ratio between APC and IPC [73].

Security Concerns. An environment that does not allow for safe, efficient transfer of information is not one in which innovation can prosper. Knowledge management, especially when coupled and integrated with external knowledge sources, requires extensive security measures to protect the validity and reliability 
of data. Lack of this security may discourage many OI organizations from sharing their data, particularly in outbound OI, due to security concerns for commercial or industrial exploitation [51]. The security measures demand more even resources from the firm, such as an adequate knowledge management system. Recovering from the mishandling of knowledge and business data in OI may put a further financial strain on the company as a whole [50], [52].

\subsection{Individual Level}

Engaging individuals in the OI process is key to successfully generating value through the various models [44], [45], [71]. Our analysis of the individual level of OI limitations discusses the idea competition effect, knowledge barriers, and individual risks concerning the success of OI. Focusing on the struggles facing those most directly involved in the innovation process allows us to pinpoint where the operational and organizational levels can better support these actors. However, we should note that recent literature only studied individual limitations that an OI organization can partially manage.

Idea Competition Effect. In OI communities such as an innovation marketplace, idea competition is often required for the sponsoring organization to select the most viable solution [27]. Although exposure to many competing ideas provides a higher chance of securing the best possible idea for successful product development, this exposure also increases the perceived constraints in the mind of the participants during the contest. Idea competition effect can negatively affect individual competitor's perception of the task and thus constrain their ability to ideate [74]. Using social mechanisms and technologies in OI models such as SPD also increases the negative effect of idea competition [75]. While collaboration among external actors may mitigate this effect, only a limited number of OI platforms, mainly in OSC, can accommodate meaningful collaboration.

Knowledge Barriers. Access to qualified external contributors is among the most common barriers to a successful OI project, with a proportion of $77 \%$ out of all the other barriers [50]. In highly specialized sectors such as manufacturing [76], OI processes can be limited by the lack of external actors with adequate industry knowledge. In the high-tech industry, recruiting qualified individuals and evaluating their skills pose significant challenges to maintain the quality of contributions. Thus, research highlights the knowledge barrier as the main limitation to sustaining a productive OI community [47]. Due to the need for such a deep understanding of technical processes in a rapidly changing industry, organizations face a knowledge gap when resorting to external sources of value creation and capture.

Individual Risk Factors. OI processes are often associated with uncertainty because of the high level of risk involved not only for the organization, but also for individual external actors [51][44]. For example, privacy concerns may limit the application of a successful OI practice. Sponsoring organizations sometimes hesitate to allow external actors to access their know-how due to IP rights concerns and at the same time share their contributions with other internal or external collaborators. Organizations that do not have a strong knowledge management system in place may run into issues with the storage and handling of important data, which could pose a risk for individual contributors. This, in turn, limits openness and collaboration [51]. Individual risk factors, however, are not limited to IP rights or privacy and may include financial, reputation, and time risks [51][44].

\section{Discussion}

This study synthesized the limitations of OI discussed in recent literature. By classifying these limitations into three groups (organizational, operational, and individual), we developed a framework rendering the key OI innovation decisions and their hierarchical relationships. Table 1 lists the limitations and Figure 3 presents our framework that illustrates the OI critical success factors.

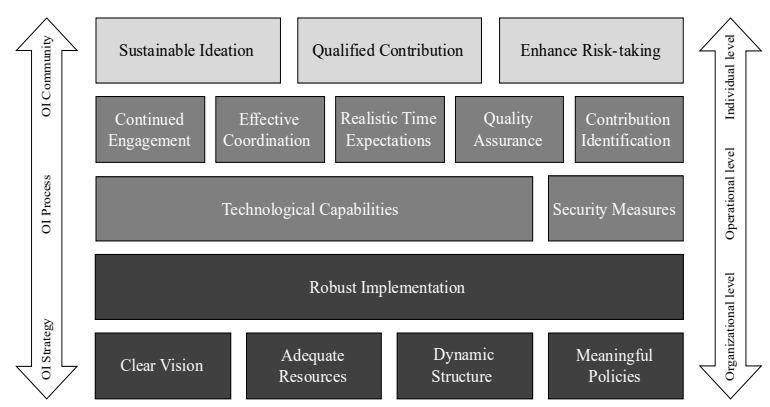

Figure 3. Critical success factors of open innovation

Our study revealed the importance of having a clear vision for OI initiatives. Uncertainty about why OI is needed may lead to aimless experimentations without significant outcomes. For example, an OI marketplace established to reduce the cost of $R \& D$ requires different mechanisms and partners compared with a customer innovation community aimed at maintaining market leadership. Resource constraints also prevent OI from successful implementation. However, there are some differences between resources required by different models. For example, an OSC may fail because of an incapable central integrator, while SPD may fail in SMEs because of limited manufacturing 
partners. Furthermore, lack of structure is a limitation that stems from a lack of focused OI vision and it is exacerbated by resource limitations. Without a set of clear expectations from OI, it is difficult to determine OI structure and thus to plan for key activities and required resources. That is why many OI intermediaries narrowed their business scope after a few years of unsuccessful experimentations. More so, lack of structure and resources may lead to ineffective implementation, which is the root cause of OI failures. Poor implementation, if not recognized early in the process, can lead to an OI model that lacks potency, adaptability, dynamism, and agility. Even if an organization eventually overcomes these limitations, OI may still fail in the absence of coherent policies and procedures (e.g., privacy compliance or fair and equitable enforcement of IP rights).

\section{Table 1. List of OI limitations identified}

\begin{tabular}{|c|c|c|c|}
\hline CATEGORIES & LIMITATION & DEFINITION & REFERENCES \\
\hline \multirow[t]{5}{*}{ Organizational } & Lack of Clear Vision & $\begin{array}{l}\text { Limitations in defining and communicating OI goals and } \\
\text { objectives with internal/external stakeholders. }\end{array}$ & {$[6],[27],[46],[47]$} \\
\hline & Resource Constraints & $\begin{array}{l}\text { Limitations in securing, allocating, and sustaining resources } \\
\text { needed for OI operation and maintenance. }\end{array}$ & $\begin{array}{l}{[6],[27],[40],[48]} \\
{[50],[51],[77]}\end{array}$ \\
\hline & Lack of Structure & $\begin{array}{l}\text { Limitations in designing viable OI structure with a clear } \\
\text { definition of roles and responsibilities. }\end{array}$ & {$[6],[45],[50],[52],[53]$} \\
\hline & Implementation Challenges & $\begin{array}{l}\text { Limitations in establishing OI processes in support of both } \\
\text { value creation and value capture. }\end{array}$ & $\begin{array}{l}{[27],[40],[41],[47]} \\
{[51],[55]-[58]}\end{array}$ \\
\hline & Compliance Concerns & $\begin{array}{l}\text { Limitations stemmed from internal and external rules and } \\
\text { regulations such as IP rights and public policy. }\end{array}$ & $\begin{array}{l}{[47],[51],[59],[60]} \\
{[62]}\end{array}$ \\
\hline \multirow[t]{7}{*}{ Operational } & Community Engagement & $\begin{array}{l}\text { Limitations in miniating external actors' participation through } \\
\text { pecuniary and non-pecuniary reward systems. }\end{array}$ & {$[47],[64]-[66],[78]$} \\
\hline & Coordination Constraints & $\begin{array}{l}\text { Limitations in coordaining OI activities and interactions } \\
\text { between internal and external actors. }\end{array}$ & $\begin{array}{l}{[45],[47],[52],[55],} \\
{[67],[68]}\end{array}$ \\
\hline & Quality Assurance & $\begin{array}{l}\text { Limitations in evaluating the quality of community's } \\
\text { contributions or controlling the outcome of ideation. }\end{array}$ & {$[45],[53]$} \\
\hline & Time Constraints & $\begin{array}{l}\text { Limitations in OI project time management due to lack of } \\
\text { enough time or inaccurate time estimate. }\end{array}$ & {$[23],[47],[51]$} \\
\hline & Technological Affordances & $\begin{array}{l}\text { Limitations in technological capabilities for managing the OI } \\
\text { process and mobilizing the OI community. }\end{array}$ & $\begin{array}{l}{[27],[52],[65],[70],} \\
{[71]}\end{array}$ \\
\hline & Identification Limitations & $\begin{array}{l}\text { Limitations in monitoring, tracking, and integrating OI } \\
\text { community members' anonymous contributions. }\end{array}$ & {$[45],[73]$} \\
\hline & Security Concerns & $\begin{array}{l}\text { Limitation in maintaining a safe and secure inbound and } \\
\text { outbound knowledge flow and knowledge management. }\end{array}$ & {$[50]-[52]$} \\
\hline \multirow[t]{3}{*}{ Individual } & Idea Competition Effect & $\begin{array}{l}\text { Limitation in keeping individual actors motivated and engaged } \\
\text { in highly competitive OI communities. }\end{array}$ & {$[27],[74],[75]$} \\
\hline & Knowledge Barriers & $\begin{array}{l}\text { Limitations in recruiting qualified individual actors with } \\
\text { adequate industry knowledge and required skills. }\end{array}$ & {$[47],[50],[76]$} \\
\hline & Individual Risk Factors & $\begin{array}{l}\text { Limitation in mitigating risks perceived by external actors } \\
\text { from IP rights and privacy to financial and time risks. }\end{array}$ & {$[51],[52]$} \\
\hline
\end{tabular}

Even with a solid foundation, OI models may fail at an operational level. Operation limitations are either technical or procedural. Lack of access to OI technology that can afford robust and secure knowledge flow and management and facilitate ideation, collaboration, and networking among the community members is an example of technical limitations. Technology is necessary but not sufficient since many OI organizations failed even with sophisticated digital platforms. Our study suggested that the success of OI operation heavily relies on engaging and motivating external actors, coordinating their efforts, and tracking and evaluating their contribution for quality assurance. These factors are independent of the OI model in use, albeit their relative importance and different implementation. For example, an OSC may fail due to limitations in coordinating distributed teams, while a crowdsourcing model may fail due to inefficiency in coordinating micro-tasks assignments.

Lastly, the quality of the OI community manifested itself as one of the main limitations of OI, especially within highly technical fields. We discussed OI organizations should observe three key characteristics of individual actors to manage the OI competition effect, recruit knowledgeable individuals and minimize their risks. Lack of access to external actors with knowledge and motivation may reduce the chance of OI success regardless of OI implementation.

\section{$5 \quad$ Future Research Avenues}

By recognizing OI limitations and their relationships, we can better understand the multitude of OI success 
factors and thereby inform OI's future research and development. The first research domain that deserves additional investigation is the motivations behind the inception of OI initiatives. There is limited research explaining why and when an organization needs to consider OI as an alternative innovation strategy. This line of research can render more realistic expectations from OI as a strategic initiative. Understanding OI organizational needs in terms of resources and structure is the second research avenue worth nothing. Future research can theorize different OI models and discuss their structures from different perspectives, such as financing and dynamic capability. Researchers can also examine the fluidity and dynamics of OI structure to inform OI model selection in light of each model limitation. This brings us to the third possible research avenue, implementation. While OI models have been well documented in the literature, the implementations of OI models have received far less attention except for OSC. Conducting longitudinal studies is recommended here since the OI implementation takes time to unfold and bears fruit. Furthermore, OI implementation is a recourseintensive process; therefore, identifying the strategic resources and mechanisms for their optimum allocation would pave the way for more systematic implementations of OI models. OI implementation in SMEs with limited resources is also a promising research topic that can potentially contribute to innovation democratization. Further investigation is also necessary on how organizations develop, implement and enforce OI rules and policies. Examining internal and external policies concerning IP rights across OI models, industries and countries is an example of such research avenues. Future research may also explore the extent to which national and international laws and regulations can affect OI. OI can be limited or thrive depending on the country or region in which it is implemented. Future studies, therefore, may include external factors such as culture (openness, sharing, transparency, and power distance) as well as social and economic factors (e.g. brand equity) in the examination of OI limitations

Apart from organizational limitations, operational limitations should also be considered in future studies. The research interests in this domain range from OI technologies to community engagement and OI coordination. While there have been notable studies on technologies used in operationalizing OSC, the utilization of digital technologies in other OI models has remained understudied. Except for OI platform affordances, our knowledge of OI platform design is limited. Further inquiry into the security of OI systems is also necessary since openness may bring great privacy and security threats; therefore, it is important to identify the threats and mitigation strategies.
Moreover, the engagement mechanisms and their effectiveness across OI models have not been fully understood yet. Developing a deeper understanding of the OI reward systems and their utility, transformability, and limits is critical to the success of OI community planning. Finding the balance between quality and quantity of contribution as well as between anonymous and identified contributions is also a topic of interest in many forms of OI. This line of research may address OI limitations such as information overload. Future research may also explore the various considerations and constraints associated with the coordination of such efforts. Research on OI coordination should go beyond OI activities (e.g., ideation, commercialization) and include topics such as value network governance and quality assurance.

For individual-related limitations, future research can be centered on the role of OI sponsors in recruiting qualified actors, maintaining their participation, and addressing their evolving needs. Our study identified three areas of study with several unanswered theoretical and practical questions. Future topics of interest may include external actor screening, community design, community auditing, competition design and optimization, individual risk identification and mitigation, and community development and retention. OI literature may also benefit from the comparison of individual limitations and associated mitigation strategies across OI models.

\section{$6 \quad$ Limitations}

This study was limited in scope and thus, inevitably, it is subject to limitations. First, our findings are limited by the nature of our methodology despite our rigorous article selection procedure. For example, important studies might be excluded from our sample due to our restriction to top-tier journals, two-year time frame, English-written articles, and certain keywords. Therefore, there may be additional limitations beyond what we have identified in this study. Second, our classification of limitations is not the only way to interpret the findings; different researchers might categorize the limitations in another way depending on the research objectives. Third, further research is needed to identify possible limitations beyond the three levels introduced by this study. For example, we did not identify OI limitations at a higher level, for example at industry or regional levels. We encourage future researchers to consider OI limitations pertaining to industry development, inter-industry coordination, regional innovation systems, national norm, and public policies (see, [20]). Fourth, our review did not allow us to examine the relationships between the identified limitations beyond what was presented in the literature. Future research may examine possible 
relationships in different contexts and for different OI models. We acknowledge that differences between OI models exist; however, the exploratory nature of this study did not allow us to examine these differences in detail. Researchers can consider these differences in detail through comparative studies.

Table 2. List of possible research questions informing future studies

\begin{tabular}{|c|c|}
\hline CATEGORIES & POSSIBLE RESEARCH QUESTIONS \\
\hline Organizational & $\begin{array}{l}\text { 1. How can organizations recognize OI needs to set a clear vision for OI model selection and implementation? } \\
\text { 2. How can organizations best approach the division of labor, partnerships, roles, and responsibilities in OI teams? } \\
\text { 3. How can organizations manage resources when opening their doors to allow external contributions? } \\
\text { 4. What are the structural changes or barriers to consider when implementing OI? } \\
\text { 5. What are the dynamic capabilities necessary for OI organizations to manage implementation challenges? } \\
\text { 6. How can SMEs overcome the limitations of resources and capital investment constraints? } \\
\text { 7. For SMEs, what are some of the biggest challenges of OI adoption that exist at the organizational level? } \\
\text { 8. How can organizations protect IP while allowing for dynamic knowledge exchange with external parties? } \\
\text { 9. How do external factors, such as local policies limit the extent to which OI can thrive? }\end{array}$ \\
\hline Operational & $\begin{array}{l}\text { 1. How can digital technologies be developed and used to support OI? } \\
\text { 2. What are the key privacy and security threats to OI systems, and what measures are needed to identify/reduce them? } \\
\text { 3. What are the best practices in OI network coordination and platform governance? } \\
\text { 4. What bottlenecks must be considered prior to take on the coordination of OI efforts? } \\
\text { 5. How can OI organizations address the issue of information overload and maintain the quality of contributions? } \\
\text { 6. How can managers develop OI reward systems that encourage innovation and maintain participation? } \\
\text { 7. What are best practices in governing the OI community and managing OI projects? }\end{array}$ \\
\hline Individual & $\begin{array}{l}\text { 1. What are some knowledge barriers to consider when recruiting participants for OI? } \\
\text { 2. How can OI organizations maintain a balance between anonymous and identified contributions? } \\
\text { 3. How can organizations minimize the impact of the Idea Competition Effect? } \\
\text { 4. What roles OI organizations play in mitigating individual risks of participating in OI (e.g. IP sharing risk)? } \\
\text { 5. What practices should organizations utilize to manage individual actors' expectations? }\end{array}$ \\
\hline
\end{tabular}

\section{References}

[1] G. Santoro, D. Vrontis, A. Thrassou, and L. Dezi, "The Internet of Things: Building a knowledge management system for open innovation and knowledge management capacity," Technol. Forecast. Soc. Change, vol. 136, pp. 347-354, Nov. 2018, doi: 10.1016/j.techfore.2017.02.034.

[2] C. Öberg and A. T. Alexander, "The openness of open innovation in ecosystems - Integrating innovation and management literature on knowledge linkages," J. Innov. Knowl., vol. 4, no. 4, pp. 211-218, Oct. 2019, doi: 10.1016/J.JIK.2017.10.005.

[3] I. L. Wu and Y. P. Hu, "Open innovation based knowledge management implementation: a mediating role of knowledge management design," J. Knowl. Manag., vol. 22, no. 8, pp. 1736-1756, Oct. 2018, doi: 10.1108/JKM-06-2016-0238.

[4] Y. Sun, J. Liu, and Y. Ding, "Analysis of the relationship between open innovation, knowledge management capability and dual innovation," Technol. Anal. Strateg. Manag., vol. 32, no. $1, \quad$ pp. 15-28, Jan. 2020, doi: 10.1080/09537325.2019.1632431.

[5] Q. Liu, Q. Du, Y. Hong, W. Fan, and S. Wu, "User idea implementation in open innovation communities: Evidence from a new product development crowdsourcing community," Inf. Syst. J., vol. 30, no. 5, pp. 899-927, Sep. 2020, doi: 10.1111/isj.12286.

[6] P. Haim Faridian and D. O. Neubaum, "Ambidexterity in the age of asset sharing: Development of dynamic capabilities in open source ecosystems," Technovation, vol. 99, p. 102125 , 2021, https://doi.org/10.1016/j.technovation.2020.102125.

[7] M. M. Naqshbandi, I. Tabche, and N. Choudhary, "Managing open innovation: The roles of empowering leadership and employee involvement climate," Manag. Decis., vol. 57, no. 3, pp. 703-723, 2019.

[8] M. Bogers et al., "The open innovation research landscape: established perspectives and emerging themes across different levels of analysis," Ind. Innov., vol. 24, no. 1, pp. 8-40, 2017, doi: 10.1080/13662716.2016.1240068.

[9] T. Kohler and M. Nickel, "Crowdsourcing business models that last," J. Bus. Strategy, vol. 38, no. 2, pp. 25-32, Apr. 2017, doi: 10.1108/JBS-10-2016-0120.

[10] D. Schlagwein and K. Fischbach, "Open Resource-Based View ( ORBV ): A Theory of Resource Openness," no. October, pp. 1-17, 2019.

[11] B. Bigliardi, G. Ferraro, T. Vergata, S. Filippelli, and F. Galati, The past, present and future of open innovation. Emerald Group Publishing Ltd., 2020.

[12] H. Chesbrough and S. Brunswicker, "A fad or a phenomenon? The adoption of open innovation practices in large firms," Research Technology Management, vol. 57, no. 2. Industrial Research Institute Inc., pp. 16-25, Mar. 01, 2014, doi: 10.5437/08956308X5702196.

[13] J. West and M. Bogers, "Open innovation: current status and research opportunities," Innov. Manag. Policy Pract., vol. 19, no. 1, pp. 43-50, Jan. 2017, doi: 10.1080/14479338.2016.1258995.

[14] N. T. Liem, N. V. Khuong, and T. H. T. Khanh, "Firm constraints on the link between proactive innovation, open innovation and firm performance," J. Open Innov. Technol. Mark. Complex., vol. 5, no. 4, 2019, doi: 10.3390/joitmc5040088.

[15] H. Chesbrough, "The future of open innovation," Res. Technol. Manag., vol. 60, no. 1, pp. 35-38, 2017, doi: 10.1080/08956308.2017.1255054.

[16] X. Xie, L. Fang, and S. Zeng, "Collaborative innovation network and knowledge transfer performance: A fsQCA approach," J. Bus. Res., vol. 69, no. 11, pp. 5210-5215, 2016, doi: 10.1016/j.jbusres.2016.04.114.

[17] K. Henttonen and H. Lehtimäki, "Open innovation in SMEs: Collaboration modes and strategies for commercialization in technology-intensive companies in forestry industry," Eur. J. Innov. Manag., vol. 20, no. 2, pp. 329-347, May 2017, doi: 10.1108/EJIM-06-2015-0047.

[18] G. Corral de Zubielqui, H. Fryges, and J. Jones, "Social media, 
open innovation \& HRM: Implications for performance," Technol. Forecast. Soc. Change, vol. 144, no. July 2017, pp. 334-347, 2019, doi: 10.1016/j.techfore.2017.07.014.

[19] J. West, A. Salter, W. Vanhaverbeke, and H. Chesbrough, "Open innovation: The next decade," Research Policy, vol. 43, no. 5. North-Holland, pp. 805-811, Jun. 01, 2014, doi: 10.1016/j.respol.2014.03.001.

[20] H. Chesbrough and M. Bogers, "Explicating Open Innovation: Clarifying an Emerging Paradigm for Understanding Innovation," in New Frontiers in Open Innovation, $\mathrm{H}$. Chesbrough, W. Vanhaverbeke, and J. West, Eds. Oxford: Oxford University Press, 2014, pp. 3-28.

[21] J. West, W. Vanhaverbeke, and H. Chesbrough, "Open Innovation: A Research Agenda," in Open Innovation: Researching a New Paradigm, 2006, pp. 285-308.

[22] G. M. K. Jesus and D. Jugend, "How can open innovation contribute to circular economy adoption? Insights from a literature review," Eur. J. Innov. Manag., 2021, doi: 10.1108/EJIM-01-2021-0022.

[23] T. P. T. Nguyen, F. Huang, and X. Tian, "A meta-analysis of the impact of open innovation on performance," J. Manag. Organ., pp. 1-18, Aug. 2021, doi: 10.1017/jmo.2021.38.

[24] F. von Briel and J. Recker, "Lessons from a failed implementation of an online open innovation community in an innovative organization," MIS Q. Exec., vol. 16, no. 1, pp. 3546, 2017, Accessed: Aug. 31, 2021. [Online]. Available: https://aisel.aisnet.org/misqeAvailableat:https://aisel.aisnet.or $\mathrm{g} / \mathrm{misqe} / \mathrm{vol} 16 / \mathrm{iss} 1 / 3$.

[25] R. Hofstetter, J. Z. Zhang, and A. Herrmann, "Successive Open Innovation Contests and Incentives: Winner-Take-All or Multiple Prizes?," J. Prod. Innov. Manag., vol. 35, no. 4, pp. 492-517, 2018, doi: 10.1111/jpim.12424.

[26] M. Bogers, H. Chesbrough, and C. Moedas, "Open innovation: Research, practices, and policies," Calif. Manage. Rev., vol. 60, no. 2, pp. 5-16, Feb. 2018, doi: $10.1177 / 0008125617745086$.

[27] O. D. Ovuakporie, K. G. Pillai, C. Wang, and Y. Wei, "Differential moderating effects of strategic and operational reconfiguration on the relationship between open innovation practices and innovation performance," Res. Policy, vol. 50, no. $1, \quad$ p. $104146, \quad 2021, \quad$ doi: https://doi.org/10.1016/j.respol.2020.104146.

[28] D. Ehls, "Open Source Project Collapse-Sources and Patterns of Failure," in Proceedings of the 50th Hawaii International Conference on System Sciences, 2017, pp. 5327-5336, Accessed: Aug. 20, 2021. [Online]. Available: http://hdl.handle.net/10125/41807.

[29] H. Chesbrough, Open Innovation Results: Going Beyond the Hype and Getting Down to Business. Oxford University Press, 2019.

[30] P. Nakagaki, J. Aber, and T. Fetterhoff, "The Challenges in Implementing Open Innovation in a Global Innovation-Driven Corporation," Res. Manag., vol. 55, no. 4, pp. 32-38, Jul. 2012, doi: 10.5437/08956308X5504079.

[31] A. Ullrich and G. Vladova, "Weighing the Pros and Cons of Engaging in Open Innovation," Technol. Innov. Manag. Rev., vol. 6, no. 4, pp. 34-40, 2018, doi: 10.22215/timreview/980.

[32] M. Bogers, H. Chesbrough, and R. Strand, "Sustainable open innovation to address a grand challenge: Lessons from Carlsberg and the Green Fiber Bottle," Br. Food J., 2020, doi: 10.1108/BFJ-07-2019-0534.

[33] M. Hossain, K. M. Z. Islam, M. A. Sayeed, and I. Kauranen, "A comprehensive review of open innovation literature," $J$. Sci. Technol. Policy Manag., vol. 7, no. 1, pp. 2-25, 2016, doi: 10.1108/JSTPM-02-2015-0009.

[34] M. S. Ramírez and F. J. García-Peñalvo, "Co-creation and open innovation: Systematic literature review," Comunicar, vol. 26, no. 54. pp. 9-18, 2018, doi: 10.3916/C54-2018-01.

[35] H. Bhimani, A. L. Mention, and P. J. Barlatier, "Social media and innovation: A systematic literature review and future research directions," Technol. Forecast. Soc. Change, vol. 144, pp. 251-269, 2019, doi: 10.1016/j.techfore.2018.10.007.

[36] M. Greco, M. Grimaldi, and L. Cricelli, "Open innovation actions and innovation performance: A literature review of European empirical evidence," Eur. J. Innov. Manag., vol. 18, no. 2, pp. 150-171, 2015, doi: 10.1108/EJIM-07-2013-0074.

[37] J. West and M. Bogers, "Leveraging external sources of innovation: A review of research on open innovation," J. Prod. Innov. Manag., vol. 31, no. 4, pp. 814-831, 2014, doi: 10.1111/jpim. 12125.

[38] J. Webster and R. T. Watson, "Analyzing the Past to Prepare for the Future: Writing a Literature Review.," MIS Q., vol. 26, no. 2, pp. xiii-xxiii, 2002, doi: 10.1.1.104.6570.

[39] Y. Levy and T. J. Ellis, "A systems approach to conduct an effective literature review in support of information systems research," Informing Sci., vol. 9, pp. 181-211, 2006, doi: $10.28945 / 479$.

[40] D. Filiou, "A new perspective on open innovation: established and new technology firms in UK bio-pharmaceuticals," $R \& D$ Manag., vol. 51, no. 1, pp. 73-86, 2021, doi: https://doi.org/10.1111/radm.12425.

[41] T. (Ya) Tang, G. J. Fisher, and W. J. Qualls, "The effects of inbound open innovation, outbound open innovation, and team role diversity on open source software project performance," Ind. Mark. Manag., vol. 94, pp. 216-228, Apr. 2021, doi: 10.1016/j.indmarman.2021.02.013.

[42] S. Durst and P. Ståhle, "Success Factors of Open InnovationA Literature Review," J. Bus. Res. Manag., vol. 4, no. 4, pp. 111-131, 2013, Accessed: Aug. 24, 2021. [Online]. Available: http://www.cscjournals.org/manuscript/Journals/IJBRM/Volu me4/Issue4/IJBRM-154.pdf.

[43] C. Han and M. Yang, "Stimulating Innovation on Social Product Development: An Analysis of Social Behaviors in Online Innovation Communities," IEEE Trans. Eng. Manag., pp. 1-11, 2020, doi: 10.1109/tem.2019.2955073.

[44] K. Abhari, E. J. E. J. Davidson, and B. B. Xiao, "A Risk Worth Taking? The Effects of Risk and Prior Experience on CoInnovation Participation," Internet Res., vol. 28, no. 3, pp. 804-828, 2018, doi: 10.1108/IntR-05-2017-0196.

[45] M. Germonprez, M. Levy, J. E. Kendall, and K. E. Kendall, "Tapestries of innovation: Structures of contemporary open source project engagements," J. Assoc. Inf. Syst., vol. 21, no. 3, pp. 615-663, 2020, doi: 10.17705/1jais.00615.

[46] E. Albats, D. Podmetina, and W. Vanhaverbeke, "Open innovation in SMEs: a process view towards business model innovation," J. Small Bus. Manag., vol. Forthcomin, pp. 1-42, Aug. 2021, doi: 10.1080/00472778.2021.1913595.

[47] A. Bertello, A. Ferraris, P. De Bernardi, and B. Bertoldi, "Challenges to open innovation in traditional SMEs: an analysis of pre-competitive projects in university-industrygovernment collaboration," Int. Entrep. Manag. J., 2021, doi: 10.1007/s11365-020-00727-1.

[48] A. Urbinati, D. Chiaroni, V. Chiesa, and F. Frattini, "The role of digital technologies in open innovation processes: an exploratory multiple case study analysis," $R$ D Manag., vol. 50, no. 1, pp. 136-160, Jan. 2020, doi: 10.1111/radm.12313.

[49] M. C. Annosi, G. Marzi, F. Ciampi, and R. Rialti, "An Ambidextrous Approach to Practice-Based Innovation for Social Product Development: Lessons From A Dutch Company," IEEE Trans. Eng. Manag., pp. 1-12, 2020, doi: 10.1109/tem.2020.2977976.

[50] R. Torres de Oliveira, S. Gentile-Lüdecke, and S. Figueira, "Barriers to innovation and innovation performance: the mediating role of external knowledge search in emerging economies," Small Bus. Econ., 2021, doi: 10.1007/s11187021-00491-8.

[51] S. Beck et al., "The Open Innovation in Science research field: a collaborative conceptualisation approach," Ind. Innov., pp. 1-50, 2020, doi: 10.1080/13662716.2020.1792274.

[52] S. Gentile-Lüdecke, R. Torres de Oliveira, and J. Paul, "Does 
organizational structure facilitate inbound and outbound open innovation in SMEs?," Small Bus. Econ., vol. 55, no. 4, pp. 1091-1112, 2020, doi: 10.1007/s11187-019-00175-4.

[53] J. Cenamor and J. Frishammar, "Openness in platform ecosystems: Innovation strategies for complementary products," Res. Policy, vol. 50, no. 1, p. 104148, 2021.

[54] M. R. Martínez-Torres, "Analysis of open innovation communities from the perspective of social network analysis," Technol. Anal. Strateg. Manag., vol. 26, no. 4, pp. 435-451, 2014.

[55] A. Cavallo, H. Burgers, A. Ghezzi, and V. van de Vrande, "The evolving nature of open innovation governance: A study of a digital platform development in collaboration with a big science centre," Technovation, p. 102370, Aug. 2021.

[56] M. I. Roldán Bravo, A. Ruiz Moreno, A. Garcia Garcia, and I. Huertas-Valdivia, "How open innovation practices drive innovation performance: moderated-mediation in the interplay between overcoming syndromes and capabilities," J. Bus. \&amp; Ind. Mark., vol. ahead-of-print, no. ahead-of-print, Jun. 2021, doi: 10.1108/JBIM-02-2020-0106.

[57] K. Diener, D. Luettgens, and F. T. Piller, "Intermediation for open innovation: comparing direct versus delegated search strategies of innovation intermediaries," Int. J. Innov. Manag., vol. 24, no. 4, Jun. 2020, doi: 10.1142/S1363919620500371.

[58] E. Gimenez-Fernandez, C. Abril, H. Breuer, and S. Gudiksen, "Gamification approaches for open innovation implementation: A conceptual framework," Creat. Innov. Manag., vol. 30, no. 3, pp. 455-474, Sep. 2021, doi: 10.1111/CAIM.12452.

[59] L. Dahlander, D. M. Gann, and M. W. Wallin, "How open is innovation? A retrospective and ideas forward," Res. Policy, vol. 50, no. 4 , p. $104218,2021$.

[60] M. Holgersson and O. Granstrand, "Value capture in open innovation markets: the role of patent rights for innovation appropriation," Eur. J. Innov. Manag., vol. ahead-of-print, no. ahead-of-print, Aug. 2021, doi: 10.1108/EJIM-02-2021-0114.

[61] A. S. Patrucco, D. Trabucchi, F. Frattini, and J. Lynch, "The impact of Covid-19 on innovation policies promoting Open Innovation," R\&D Manag., Jul. 2021.

[62] E. R. Gold, "The fall of the innovation empire and its possible rise through open science," Res. Policy, vol. 50, no. 5, p. 104226, Jun. 2021, doi: 10.1016/j.respol.2021.104226.

[63] O. Gassmann, E. Enkel, and H. Chesbrough, "The future of open innovation," R\&D Manag., vol. 40, no. 3, pp. 213-221, 2010, doi: 10.1111/j.1467-9310.2010.00605.x.

[64] T. A. Suhada, J. A. Ford, M.-L. Verreynne, and M. Indulska, "Motivating individuals to contribute to firms' non-pecuniary open innovation goals," Technovation, vol. 102, p. 102233, 2021.

[65] K. Abhari, E. J. Davidson, and B. Xiao, "Modeling Social Product Development Process, Technology, and Governance," IEEE Trans. Eng. Manag., pp. 1-14, 2020.4.

[66] K. Abhari, E. J. Davidson, and B. Xiao, "Collaborative innovation in the sharing economy: Profiling social product development actors through classification modeling," Internet Res., vol. 29, no. 5, pp. 1014-1039, 2019.

[67] C. Marullo, J. M. Ahn, I. Martelli, and A. Di Minin, "Open for innovation: An improved measurement approach using item response theory," Technovation, p. 102338, Jul. 2021.

[68] D. L. Roberts, R. Palmer, and M. Hughes, "Innovating the product innovation process to enable co-creation," $R D$ Manag., 2021, doi: 10.1111/radm.12492.

[69] L. Souza, I. Ramos, and J. Esteves, "Crowdsourcing Innovation: A Risk Management Approach," in Mediterranean Conference on Information Systems Proceedings, 2009, pp. 763-774.

[70] S. Wu, X. Ding, R. Liu, and H. Gao, "How does IT capability affect open innovation performance? The mediating effect of absorptive capacity," Eur. J. Innov. Manag., vol. 24, no. 1, pp.
43-65, Jan. 2021, doi: 10.1108/EJIM-02-2019-0043.

[71] K. Abhari, E. J. Davidson, and B. Xiao, "Inventing Together: The Role of Actor Goals and Platform Affordances in Open Innovation," J. Assoc. Inf. Syst., 2021.

[72] A. K. Zobel, "Benefiting from Open Innovation: A Multidimensional Model of Absorptive Capacity*," J. Prod. Innov. Manag., vol. 34, no. 3, pp. 269-288, May 2017.

[73] S. L. Daniel, T.-T. R. Chung, and P. N. Sharma, "The Impact of Anonymous Peripheral Contributions on Open Source Software Development," AIS Trans. Human-Computer Interact., vol. 12, no. 3, pp. 146-171, 2020.

[74] R. Hofstetter, D. W. Dahl, S. Aryobsei, and A. Herrmann, "Constraining Ideas: How Seeing Ideas of Others Harms Creativity in Open Innovation," J. Mark. Res., vol. 58, no. 1, pp. 95-114, 2021.

[75] D. Fischer, J. Prasuhn, S. Strese, and M. Brettel, "The role of social media for radical innovation in the new digital age," Int. J. Innov. Manag., p. 2150075, Aug. 2021

[76] S. Lai-Yin Cheah, Y.-P. Ho, and S. Li, "Search strategy, innovation and financial performance of firms in process industries," Technovation, p. 102257, 2021.

[77] G. Barrett, L. Dooley, and J. Bogue, "Open innovation within high-tech SMEs: A study of the entrepreneurial founder's influence on open innovation practices," Technovation, vol. 103, p. 102232, 2021.

[78] O. A. Acar, "Motivations and solution appropriateness in crowdsourcing challenges for innovation," Res. Policy, vol. 48, no. 8, pp. 1-13, 2019, doi: 10.1016/j.respol.2018.11.010.

\section{Appendix A: List of Journals}

Academy of Management Journal; Academy of Management Review; Administrative Science Quarterly; AIS Transactions on Human-Computer Interaction; American Economic Review; Communications of the AIS; Computers in Human Behavior; Decision Support Systems; Economics of Innovation and New Technology; Entrepreneurship and Regional Development; Entrepreneurship Theory and Practice; European Journal of Information Systems; European Journal of Innovation Management; Human-Computer Interaction; IEEE Transactions on Management; Industry and Innovation; Information \& Management; Information \& Organization; Information Systems Frontiers; Information Systems Journal; Information Systems Research; Information Technology \& People; International Entrepreneurship and Management Journal; International Journal of Entrepreneurial Behaviour \& Research; International Journal of Information Management; International Journal of Innovation Management; International Small Business Journal; Internet Research; Journal of AIS; Journal of Business Venturing; Journal of Economic Literature; Journal of Finance; Journal of Information Technology; Journal of Intellectual Capital; Journal of Management; Journal of Management Studies; Journal of Marketing; Journal of Marketing Research; Journal of MIS; Journal of Product Innovation Management; Journal of Small Business Management; Journal of Strategic Information Systems; Management Science; MIS Quarterly; Organization Behavior and Human Decision Processes; Organization Studies; Quarterly Journal of Economics; R\&D Management; Research Policy; Small Business Economics; Small Business Economics; Strategic Entrepreneurship Journal; Strategic Management Journal; Strategic Organization; Technology Analysis \& Strategic Management; and Technovation. 